\title{
Theoretical model of rare earth ions doping amount in high silica luminescence glass
}

\author{
Linjiao Ren, Xiaohua Lei $^{1}$, Weimin Chen, Xiaoqing Du, Lei jin \\ The Key Lab. for Optoelectronic Technology \& Systems of Ministry of \\ Education, Department of Opto-Electronics Engineering, Chongqing University, \\ Chongqing, 400044, China
}

\begin{abstract}
:
To obtain the quantitative doping amount of rare earth ions in high silica glass, the RE ions diffusing into pores and adsorbed on the surface of pores by ion-exchange were both considered and the theoretical model of the doping amount was established. The results show that the adsorption quantity of ion-exchange is only about one-tenth of diffusion fluxes. So to improve the doping amount of RE ions in high silica glass, increasing the doping solution concentration is the easiest way and increasing the specific surface area of porous glass is not an efficient method. The absorbance of sintered porous glasses with the different content of $\mathrm{Ce}^{3+}$ and $\mathrm{Sm}^{3+}$ were measured to prove the calculation results of doping amount, qualitatively. The results indicated that the absorbance of different samples grows in line with the doping amount trend.
\end{abstract}

Keywords: adsorption, rare earth ions, adsorption amount, diffusion, absorbance

\section{Introduction}

The high silica luminescence glass sintered by rare earth (RE) ions doped porous glass is a kind of potential luminescent materials for White LEDs, because of its excellent chemical stability and fine mechanical properties ${ }^{[1-4]}$. It can also be used to prepare special optical fibers, on account of its high content of $\mathrm{SiO}_{2}$. Luminous intensity of rare earth ions doped high silica glass is mainly influenced by the doping

\footnotetext{
${ }^{1}$ Corresponding author: Xiaohua Lei

Fax NO.:+86 023 65103126; E-mail addresses: xhlei@ cqu.edu.cn.
} 
amount of rare earth ions. Before concentration quenching, the luminescent intensity of high silica glass is stronger with the increase doping amount of rare earth ions, but the luminescent intensity of high silica glass will decrease after concentration quenching $^{[5]}$. So, it is necessary to optimize the doping amount of rare earth ions to improve the luminous intensity of high silica glass.

The doping amount of RE ions in high silica glass can be influenced by the concentrations of RE ion solution, adsorption time, solution temperatures, the parameters of porous glass and, so on ${ }^{[6]}$. Researchers studied the optimization of rare earth ions doping amount emphatically by the experimental method, such as high silica glasses doped by $\mathrm{Ce}^{3+[7]}, \mathrm{Eu}^{2+[8,9]}, \mathrm{Tb}^{3+[10]}, \mathrm{Eu}^{3+[11]}, \mathrm{Sm}^{3+}$, and so on. Without quantitative analysis theory of doping amount, the optimal doping amount of rare earth ions can be obtained by a series of experiments, such as adjustments of process parameters, preparations of glass samples, testes of emission spectra. If the doping amount of RE ions in high silica glass can be calculated by theoretical model, a lot of time and resources can be saved at experimental stage. Some analytical methods have been researched in the adsorption and desorption processes of porous media ${ }^{[12]}$, such as the theory of adsorptive isotherm ${ }^{[13]}$, the simulation of molecular dynamics ${ }^{[14-17]}$ and the principle of fluid diffusion ${ }^{[18,19]}$. While in high silica glass, there are still no quantitative models to obtain the doping amount of rare earth ions, efficiently.

To quantify the doping amount of RE ions in high silica glass before experiments, the middle process of adsorption and desorption were ignored and the static results were analyzed emphatically. A modified diffusion equation was inferred to calculate the doping amount of RE ions, which considered the chemical reactions between RE ions and porous glasses. Besides, to avoid the instability of porous materials, the absorbance of sintered porous glasses were measured to prove the simulation results of RE ions doping amount, qualitatively. Although the simulation results of this method were not accurate because of many assumptions, it is very simply and quickly for guiding experiments. 


\section{Theoretical model of rare earth ions doping amount}

The porous glasses were immersed into RE ions solution for a long time to prepare RE ions doped porous glasses. The structure diagram of RE ions doped porous glass is shown in Fig.1, the total RE ions in porous glasses can be divided into two classes: one class of ions were adsorbed on the surface of pores because of ion-exchange process ${ }^{[20-22]}$ and the other ions were in the solution located in pores according to the fluid diffusion.
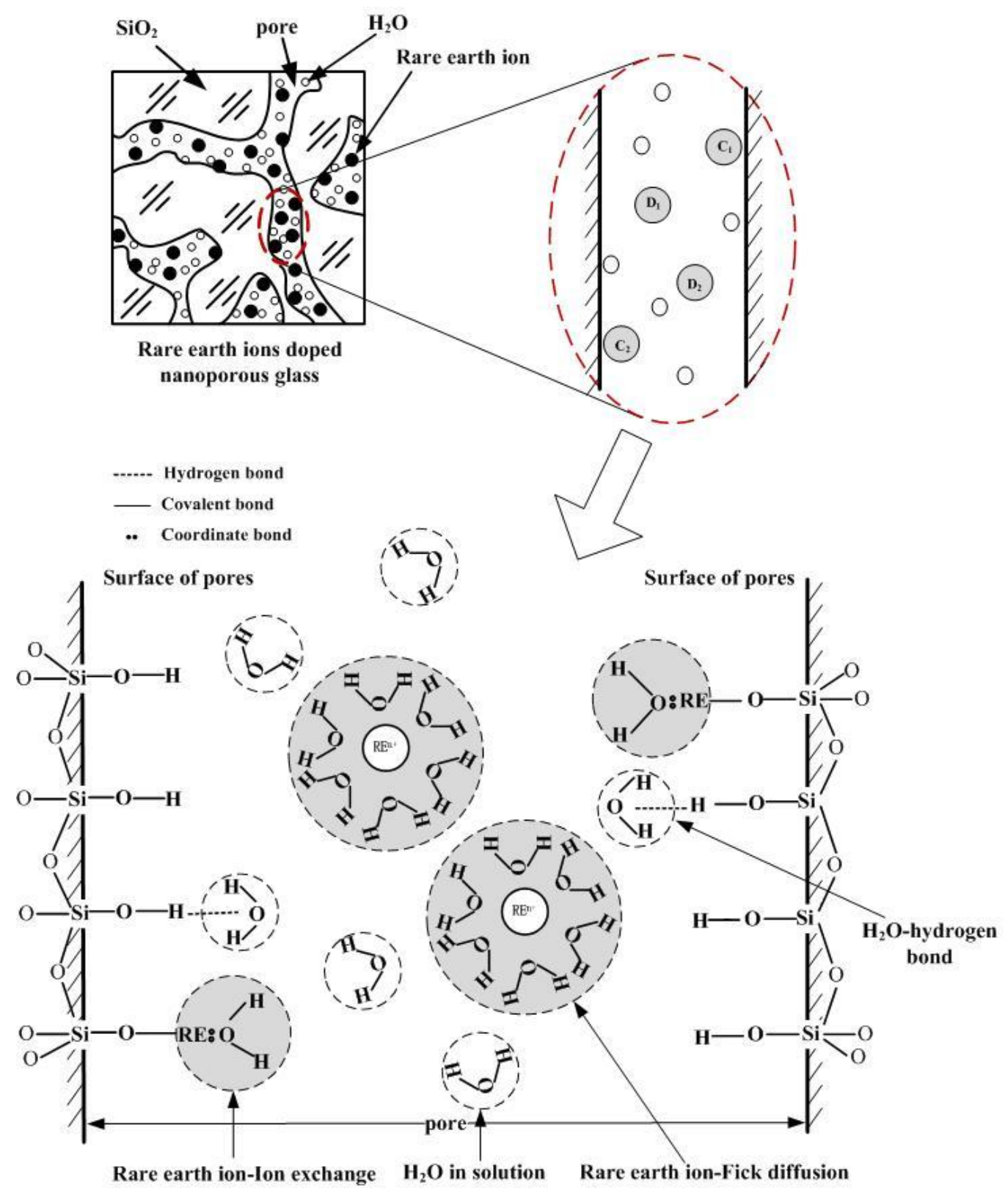
Fig.1 Structure diagram of Nano porous glass doped by rare earth ions

In the sintering process of RE ions doped porous glass, the RE ions cannot escape from glass because of the very low vapor pressure ${ }^{[23]}$. So the total doping amount $\left(\mathrm{N}_{\text {total }}\right)$ in the sintered porous glass includes the RE ions diffusing into pores $\left(\mathrm{N}_{\mathrm{D}}\right)$ and the ions adsorbed on the surface of pores by ion-exchange process $\left(\mathrm{N}_{\mathrm{C}}\right)$.

$$
N_{\text {total }}=N_{D}+N_{C}
$$
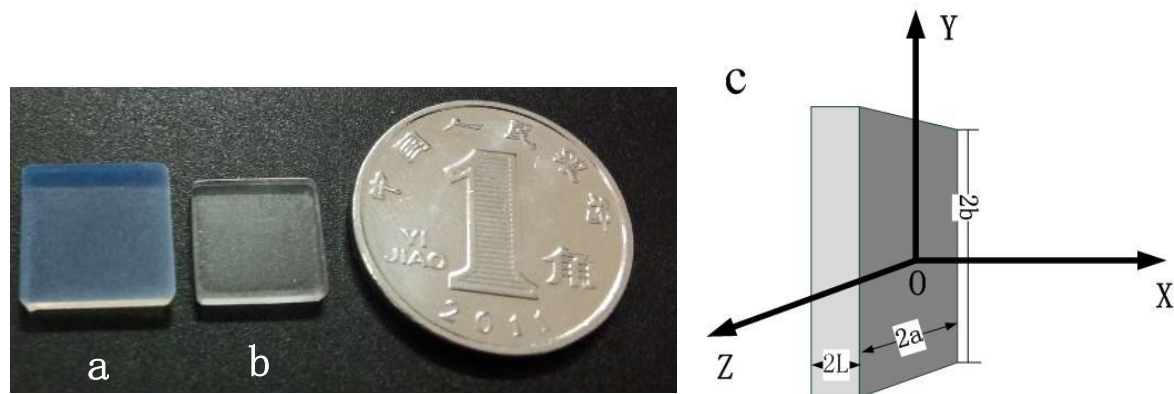

Fig.2 (a) Photograph of nonporous glass (b) Photograph of high silica luminescence glass after polishing (c) Three-dimensional system of coordinate for RE ion diffusion

The average range of pore size of the porous glass is between 3 and $15 \mathrm{~nm}$. The hydrated radii of RE ions are about 4-5 $\mathrm{A}^{[24-27]}$. The mean free path of liquid molecules is so short that usually be ignored. The pore size of porous glass is considerably larger than hydrated radiuses of RE ions and mean free path of liquid molecules ${ }^{[28]}$, so the diffusion of RE ions in porous glass should follow Fick's law of diffusion. According to the equation of mass conservation ${ }^{[29]}$, we got the diffusion equation of RE ions in porous glass, as shown in formula (2).

$$
\begin{aligned}
& \frac{\partial C_{R E}}{\partial t}=D_{R E}\left(\frac{\partial^{2} C_{R E}}{\partial x^{2}}+\frac{\partial^{2} C_{R E}}{\partial y^{2}}+\frac{\partial^{2} C_{R E}}{\partial z^{2}}\right)+\mathrm{r}_{R E} ; \\
& t=0,0<x<L, C_{R E}=0 ; \quad t=0, x>L, C_{R E}=C_{0} ; t \geq 0, x=0, \frac{\partial C_{R E}}{\partial x}=0 ; \\
& t=0,0<y<a, C_{R E}=0 ; \quad t=0, y>a, C_{R E}=C_{0} ; t \geq 0, y=0, \frac{\partial C_{R E}}{\partial y}=0 ; \\
& t=0,0<z<b, C_{R E}=0 ; \quad t=0, z>b, C_{R E}=C_{0} ; \quad t \geq 0, z=0, \frac{\partial C_{R E}}{\partial z}=0 ;
\end{aligned}
$$

In this formula, $\mathrm{C}_{\mathrm{RE}}$ is the concentration distribution of $\mathrm{RE}$ ions in porous 
glass; $\mathrm{C}_{0}$ is the concentration of $\mathrm{RE}$ ion solution before diffusion. $\mathrm{D}_{\mathrm{RE}}$ is the diffusion coefficient. $\mathrm{t}$ is diffusion time. $\mathrm{x}, \mathrm{y}$ and $\mathrm{z}$ is the diffusion distance of $\mathrm{RE}$ ions in three ways, as indicated in Fig.2(c). $\mathrm{r}_{\mathrm{RE}}$ is the reduction rate of $\mathrm{RE}$ ions because of ion-exchange. The dimensions of porous glass are $2 a^{*} 2 b^{*} 2 \mathrm{~L}(\mathrm{a}=\mathrm{b}=5 \mathrm{~mm}, \mathrm{~L}=1 \mathrm{~mm})$.

The formula is too complex to obtain its analytical solution. If the diffusion coefficient $\mathrm{D}_{\mathrm{RE}}$ is considered as a constant which is not all about diffusion time and distance, as shown in Eq.3, the diffusion process in three directions can be thought independent. Besides the thickness of porous glass is $2 \mathrm{~mm}$ which is much less than its length and width (10mm). So when we get equilibrium in $\mathrm{X}$ direction, we can also consider that the other directions have got diffusion balance and the Eq.2 can be simplified as Eq.4.

$$
\begin{gathered}
\mathrm{D}_{R E}=\frac{\varepsilon}{\tau} \frac{\mathrm{kT}}{6 \pi \mu_{\mathrm{B}} \mathrm{r}_{\mathrm{H}}} \\
\frac{\partial C_{A x}}{\partial t}=D_{A} \frac{\partial^{2} C_{A x}}{\partial x^{2}}+S_{a} N_{O H} \eta \frac{\bar{C}_{A x}}{\partial t} \\
t=0,0<x<L, C_{A x}=0 ; t=0, x>L, C_{A x}=C_{0} ; t \geq 0, x=0, \frac{\partial C_{A x}}{\partial x}=0 ;
\end{gathered}
$$

In Eq.3, $\mathrm{r}_{\mathrm{H}}$ is the hydrated radius of $\mathrm{RE}$ ion. $\mathrm{T}$ is absolute temperature. $\mathrm{k}=1.38 \times 10^{-23} \mathrm{~J} / \mathrm{K}$. The viscosity of water $\mu_{\mathrm{B}}=1.14 \times 10^{-3} \mathrm{~Pa} . \mathrm{S} . \varepsilon$ is porosity of porous glass and the tortuosity factor $\tau$ can be estimated by $\tau=0.8(1-\varepsilon)+1$. Eq.4 shows some influence factors of $r_{R E}$. The reduction rate of $R E$ ions $\left(r_{R E}\right)$ because of ion-exchange can be influenced by the concentration of surface hydroxyl, the surface area of porous glass $\left(\mathrm{S}_{\mathrm{a}}\right)$, the diffusion time and distance. $\mathrm{N}_{\mathrm{OH}}$ is mole numbers of surface hydroxyl groups per unit area. $\eta$ is the probability of ion-exchange.

The diffusion process is time-consuming, but the time of ion-exchange can be ignored. To simplify the differential equation Eq.4, we can assume that the two kinds of adsorptions are separate in time. The diffusion comes first and then the ion-exchange occurs, so $\mathrm{r}_{\mathrm{RE}}$ in Eq.4 can be removed to calculate the diffusion fluxes 
of RE ions, as shown in Eq.5.

$$
\begin{aligned}
& \frac{\partial C_{R E}}{\partial t}=D_{R E} \frac{\partial^{2} C_{R E}}{\partial x^{2}} \\
& t=0,0<x<L, C_{R E}=0 ; t=0, x>L, C_{R E}=C_{0} ; t \geq 0, x=0, \frac{\partial C_{R E}}{\partial x}=0 ;
\end{aligned}
$$

Solving this differential equation, we can get the concentration distribution of RE ions in porous glass, as shown in Eq.6. We can also obtain the average concentration of $\mathrm{RE}$ ions $\left(\bar{C}_{R E}\right)$ in porous glass by doing integrals over $\mathrm{C}_{\mathrm{RE}}$. The range of integration is between $-\mathrm{L}$ and $+\mathrm{L}$. The diffusion flux of $\mathrm{RE}$ ions $\left(\mathrm{N}_{\mathrm{D}}\right)$ is equal to the product of average concentration of RE ions $\left(\bar{C}_{R E}\right)$ and pore volume of porous glass $\left(\mathrm{V}_{\mathrm{p}}\right)$, as indicated in Eq.7.

$$
\begin{aligned}
C_{R E} & =C_{0}+\sum_{n=0}^{\infty} \frac{4 C_{0} \times(-1)^{n+1}}{(2 n+1) \pi} e^{-\left[\frac{(2 n+1) \pi}{2 L}\right]^{2} D_{R E} t} \cos \left[\frac{(2 n+1) \pi}{2 L} x\right] \\
N_{D} & =\bar{C}_{R E} \times V_{p}=\frac{\int_{-L}^{L} C_{R E} d x}{2 L} \times V_{p} \\
& =\left\{\begin{array}{l}
C_{0}+\sum_{n=0}^{\infty} \frac{4 C_{0} \times(-1)^{n+1}}{(2 n+1) \pi} e^{-\left[\frac{(2 n+1) \pi}{2 L}\right]^{2} t D_{R E}} \\
\frac{2}{(2 n+1) \pi} \sin \left[\frac{(2 n+1) \pi}{2}\right]
\end{array}\right\} \times V_{p}
\end{aligned}
$$

Hydrogen bonding and electrostatic interaction are important driving forces for $\mathrm{H}_{2} \mathrm{O}-\mathrm{SiOH}$ interaction ${ }^{[30]}$ and ion-exchange. To get quantitative results, we assumed that the probabilities of $\mathrm{RE}^{3+}$ ions and water molecules absorbed on the surface of pores by $\mathrm{Si}-\mathrm{OH}$ are $\eta_{R E^{3+}}$ and $\eta_{\mathrm{H}_{2} \mathrm{O}}$, as shown in Eq.8. $\mathrm{r}$ is the distance between absorbed ions and internal surface of pores. $F_{e}$ is the electrostatic interaction between $\mathrm{RE}^{3+}$ ions and $\mathrm{Si}-\mathrm{OH}$. Hydrogen bonding cannot be expressed in terms of equations. Here, we use the electrostatic interactions $\left(F_{\mathrm{H}}\right)$ between one lone pair electrons and one hydrogen atom to quantify the hydrogen bonding interactions between water 
molecules and $\mathrm{Si}-\mathrm{OH}^{[31]}$.

$$
\eta_{R E^{3+}}=\frac{F_{e}}{\mathrm{r}_{\mathrm{H}}}=\frac{3 k e^{2}}{\mathrm{r}_{\mathrm{H}} r^{2}} ; \quad \eta_{\mathrm{H}_{2} \mathrm{O}}=\frac{F_{\mathrm{H}}}{\mathrm{r}_{\mathrm{H}_{2} \mathrm{O}}}=\frac{2 k e^{2}}{\mathrm{r}_{\mathrm{H}_{2} \mathrm{O}} r^{2}}
$$

For the same surface hydroxyl groups, both $\mathrm{RE}^{3+}$ ions and water molecules may be absorbed. The percentages of them were expressed in Eq.9. Combine the amount of surface hydroxyl groups and the RE ions concentration, the adsorption quantity of ion-exchange $\mathrm{N}_{\mathrm{C}}$ was expressed in Eq.10.

$$
\begin{gathered}
\eta_{R E}=\frac{\eta_{\mathrm{RE} E^{3+}}}{\eta_{\mathrm{R} E^{3+}}+\eta_{\mathrm{H}_{2} \mathrm{O}}} ; \eta_{\mathrm{H}_{2} \mathrm{O}}=\frac{\eta_{\mathrm{H}_{2} \mathrm{O}}}{\eta_{\mathrm{R} E^{3+}}+\eta_{\mathrm{H}_{2} \mathrm{O}}} \\
N_{C}=S_{a} N_{O H} \frac{\eta_{\mathrm{RE}}}{\eta_{\mathrm{RE}}+\eta_{\mathrm{H}_{2} \mathrm{O}}} \frac{\bar{C}_{R E}}{\bar{C}_{R E}+55.56}
\end{gathered}
$$

In conclusion, the total doping amount $\mathrm{N}_{\text {total }}$ is the sum of diffusion fluxes $\mathrm{N}_{D}$ and adsorption quantity of ion-exchange $\mathrm{N}_{\mathrm{C}}$, as indicated in Eq.11. If we know the parameters of porous glasses and doping solutions, we can simply calculate the doping amounts of glass samples before experiments.

$$
\begin{aligned}
N_{\text {total }}= & \left\{\begin{array}{l}
C_{0}+\sum_{n=0}^{\infty} \frac{4 C_{0} \times(-1)^{n+1}}{(2 n+1) \pi} e^{-\left[\frac{(2 n+1) \pi}{2 L}\right]^{2} \frac{\varepsilon}{\tau} \frac{\mathrm{kTt}}{6 \pi \mu_{\mathrm{B}} \mathrm{r}_{\mathrm{A}}}} \\
\frac{2}{(2 n+1) \pi} \sin \left[\frac{(2 n+1) \pi}{2}\right]
\end{array}\right\} \times V_{p} \\
& +S_{a} N_{O H} \frac{\eta_{\mathrm{RE}}}{\eta_{\mathrm{R} E}+\eta_{\mathrm{H}_{2} O}} \frac{\bar{C}_{R E}}{\bar{C}_{R E}+55.56}
\end{aligned}
$$

\section{Experimental}

To verify the correctness of this theoretical method, we prepared different glass samples with different doping conditions. In the preparation, the chemical composition of starting materials was $68 \mathrm{SiO}_{2}-22.5 \mathrm{~B}_{2} \mathrm{O}_{3}-8.0 \mathrm{Na}_{2} \mathrm{O}$ (wt.\%). The glass samples were cut to size $10 \mathrm{~mm} * 10 \mathrm{~mm} * 2 \mathrm{~mm}$. The borosilicate glasses were heated at $620{ }^{\circ} \mathrm{C}$ for $30 \mathrm{~h}$ to realize phase separation. The porous glasses were fabricated by removing the borate phase from phase-separated glasses in hot acid solution. The 
structure properties of interconnected pores were characterized by Brunauer, Emmett, and Teller (BET) method in a micomeritics ASAP 2010 physisorption analyser at 77K. The specific surface area, pore volume and average pore size were $84.93 \mathrm{~m}^{2} / \mathrm{g}$, $0.164 \mathrm{~cm}^{3} / \mathrm{g}$ and $7.74 \mathrm{~nm}$ respectively. The adsorption time was 6 hours and the temperature is $25^{\circ} \mathrm{C}$. By changing the concentrations of $\mathrm{Ce}^{3+}$ solution (from $0.00025 \mathrm{~mol} / \mathrm{L}$ to $0.035 \mathrm{~mol} / \mathrm{L}$, as shown in Table 1) and $\mathrm{Sm}^{3+}$ solution (from $0.01 \mathrm{~mol} / \mathrm{L}$ to $0.15 \mathrm{~mol} / \mathrm{L}$, as shown in Fig.5), we got different porous glass samples with different doping amounts. For easy measurements the RE ions doped porous glass samples were sintered at $1000^{\circ} \mathrm{C}$.

The Ultraviolet and Visible (UV) absorption spectra were measured by shimadzu UV2450 spectrophotometer over a spectral range of $220 \mathrm{~nm}-390 \mathrm{~nm}$. The thickness of raw borosilicate glass is $(2.00 \pm 0.02) \mathrm{mm}$ and the sintered samples were polished to $(1.5 \pm 0.02) \mathrm{mm}$ for measurements. All the measurements were carried out at room temperature.

\section{Results and discussion}

To avoid the instability of porous materials with respect to the relative humidity, the absorbance of sintered porous glass were measured to prove the simulation results of doping amounts. Not only the sintered porous glass has good chemical stability and thermal tolerance, but there also is a significant linear correlation between absorbance and doping amount. According to Lambert-Beer and Kubelk-Munk theory ${ }^{[32]}$, Eq.12 indicated their relationships.

$$
A=\varepsilon_{0} b c
$$

A is absorbance. $\varepsilon_{0}$ is molar absorption coefficient, $\mathrm{dm}^{3} \cdot \mathrm{mol}^{-1} \cdot \mathrm{cm}^{-1} \cdot \mathrm{b}$ is the thickness of sintered porous glass, cm. $c$ is the concentration of RE ions in glass samples, mol $\cdot \mathrm{cm}^{-3}$, which is decided by the doping amount $\left(\mathrm{N}_{\text {total }}\right)$ of RE ions in high silica glass. The UV absorption spectra of high silica glasses with different $\mathrm{Ce}^{3+}$ concentrations are described in Fig.3. The characteristic absorption band of $\mathrm{Ce}^{3+}$ peaks at about $310 \mathrm{~nm}$ according to $4 \mathrm{f}-5 \mathrm{~d}$ transition ${ }^{[33,34]}$. 


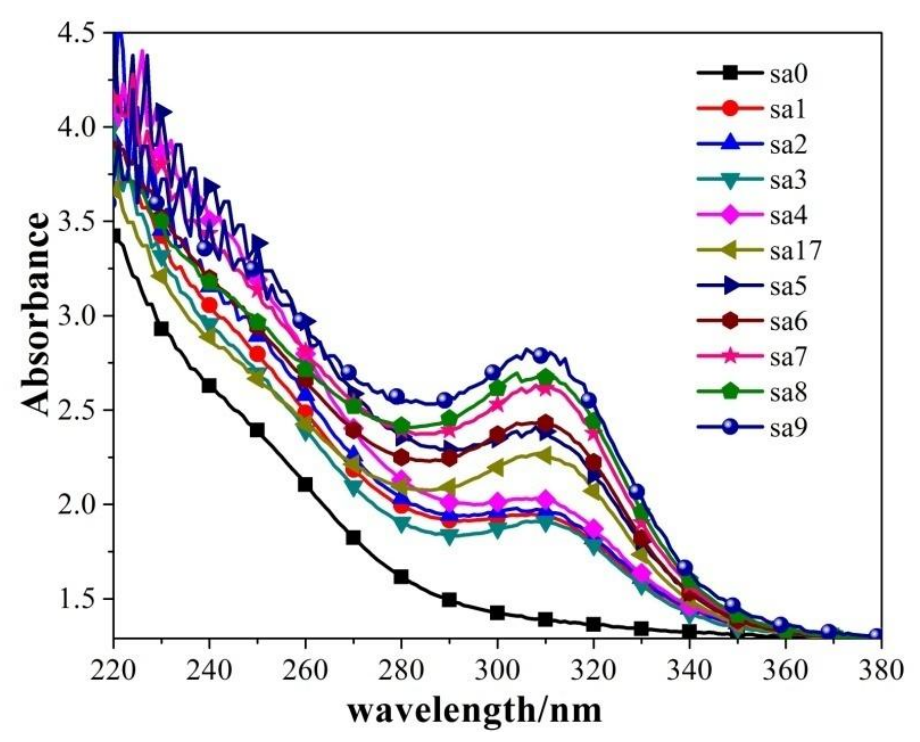

Fig.3 UV absorption spectra of high silica glasses with different concentrations of $\mathrm{Ce}^{3+}$

According to Eq.11, the diffusion fluxes $\mathrm{N}_{\mathrm{D}}$, the adsorption quantity of ion-exchange $\mathrm{N}_{\mathrm{C}}$ and the total doping amount $\mathrm{N}_{\text {total }}$ are listed in table 1. It shows that the adsorption quantity of ion-exchange is only about one-tenth of diffusion fluxes. So it is not an efficient method to add the specific surface area of porous glass to increase RE ions doping amount. The doping amount of rare earth ions can significantly increase with the growing of solution concentrations. The theoretical analysis further proved that increasing the doping solution concentration is the easiest way to increase the doping amount of rare earth ions in high silica glass.

Table. 1 Measured absorbance of 310nm, calculated diffusion fluxes, adsorption quantity of ion-exchange and doping amount of sintered glass samples with different $\mathrm{Ce}^{3+}$ concentrations

\begin{tabular}{cccccc}
\hline $\begin{array}{c}\text { Sample } \\
\text { number }\end{array}$ & $\begin{array}{c}\mathrm{Ce}^{3+} \text { concentration } \\
/ \mathrm{mol} / \mathrm{L}\end{array}$ & $\begin{array}{c}\text { Absorbance } \\
\text { of } 310 \mathrm{~nm}\end{array}$ & $\begin{array}{c}\mathrm{N}_{\mathrm{D}} \\
/ 10^{-5} \mathrm{~mol} / \mathrm{g}\end{array}$ & $\begin{array}{c}\mathrm{N}_{\mathrm{C}} \\
/ 10^{-5} \mathrm{~mol} / \mathrm{g}\end{array}$ & $\begin{array}{c}\mathrm{N}_{\text {total }} \\
/ 10^{-5} \mathrm{~mol} / \mathrm{g}\end{array}$ \\
\hline $\mathrm{Sa} 0$ & 0 & 0 & 0 & 0 & 0 \\
$\mathrm{Sa} 1$ & 0.00025 & 0.551 & 0.004108 & 0.000282 & 0.00439 \\
$\mathrm{Sa} 2$ & 0.0005 & 0.567 & 0.008217 & 0.000573 & 0.00879 \\
$\mathrm{Sa} 3$ & 0.001 & 0.519 & 0.016433 & 0.00115 & 0.01758 \\
$\mathrm{Sa} 4$ & 0.005 & 0.637 & 0.082165 & 0.00574 & 0.08790 \\
$\mathrm{Sa} 17$ & 0.01 & 0.871 & 0.16433 & 0.01148 & 0.17581 \\
$\mathrm{Sa} 5$ & 0.015 & 0.998 & 0.246495 & 0.01722 & 0.26371 \\
$\mathrm{Sa} 6$ & 0.02 & 1.043 & 0.32866 & 0.02296 & 0.35162 \\
$\mathrm{Sa} 7$ & 0.025 & 1.225 & 0.410825 & 0.0287 & 0.43952 \\
$\mathrm{Sa} 8$ & 0.03 & 1.284 & 0.49299 & 0.03443 & 0.52742 \\
$\mathrm{Sa} 9$ & 0.035 & 1.383 & 0.575155 & 0.04017 & 0.61532 \\
\hline
\end{tabular}


Fig.4 shows glass samples' absorbance of 310nm and calculated doping amount vs. the concentration of $\mathrm{Ce}^{3+}$ solution. The values have subtracted the absorbance of blank sample $(\mathrm{Sa} 0)$ at $310 \mathrm{~nm}$, as listed in Table 1 . The absorbance of different samples grows in line with total adsorption amount growths, which verifies the correctness of adsorption model, qualitatively.

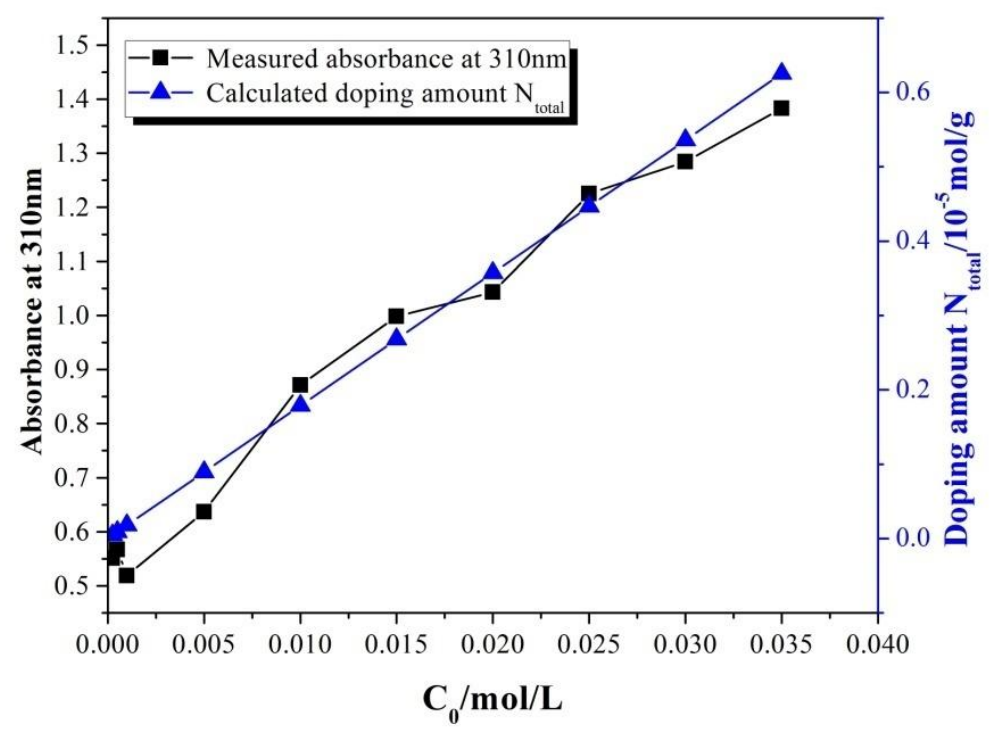

Fig.4 Measured absorbance of 310nm and calculated doping amount vs. the concentration of $\mathrm{Ce}^{3+}$ solution

In the same way, the UV absorption spectra of high silica glass samples prepared with different concentrations of $\mathrm{Sm}^{3+}$ were measured, as described in Fig.5. The absorption peak of $\mathrm{Sm}^{3+}$ is at about $401 \mathrm{~nm}$ according to $\mathrm{f}-\mathrm{f}$ transition ${ }^{[35,36]}$. Because of smaller molar absorption coefficient, the absorbance of $\mathrm{Sm}^{3+}$ at $401 \mathrm{~nm}$ is very small. On this occasion, it is necessary to obtain the doping amount of $\mathrm{Sm}^{3+}$ by theoretical method. 


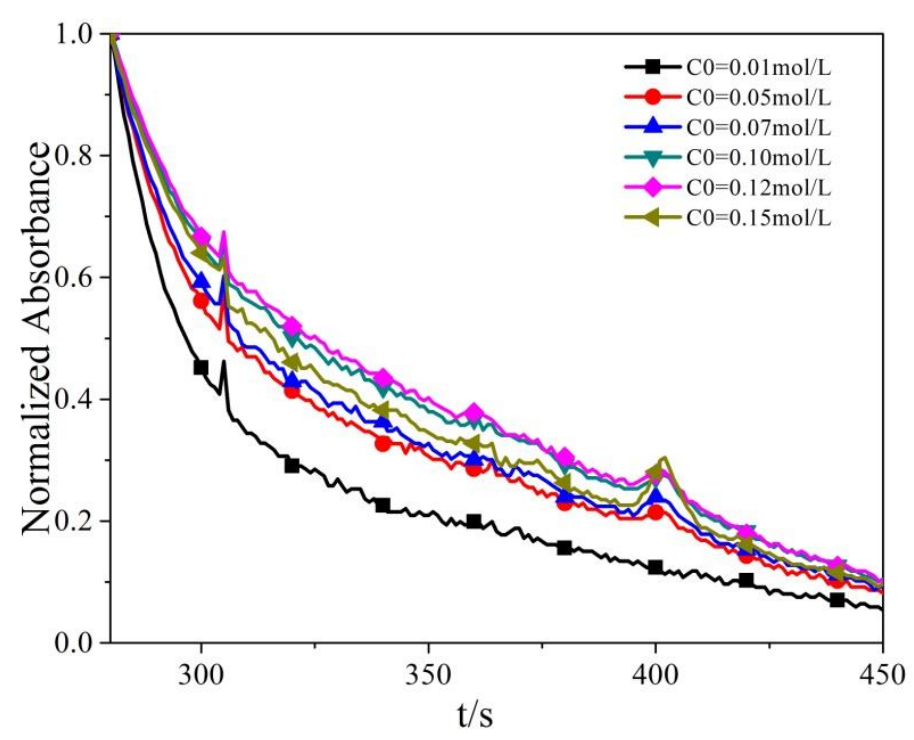

Fig.5 UV absorption spectra of high silica glasses with different concentrations of $\mathrm{Sm}^{3+}$

Fig.6 shows the glass samples' absorbance of 401nm and total doping amount vs. the concentration of $\mathrm{Sm}^{3+}$ solution. Theoretical and experimental results have the same trend of variability, which further validated the correctness of theoretical model.

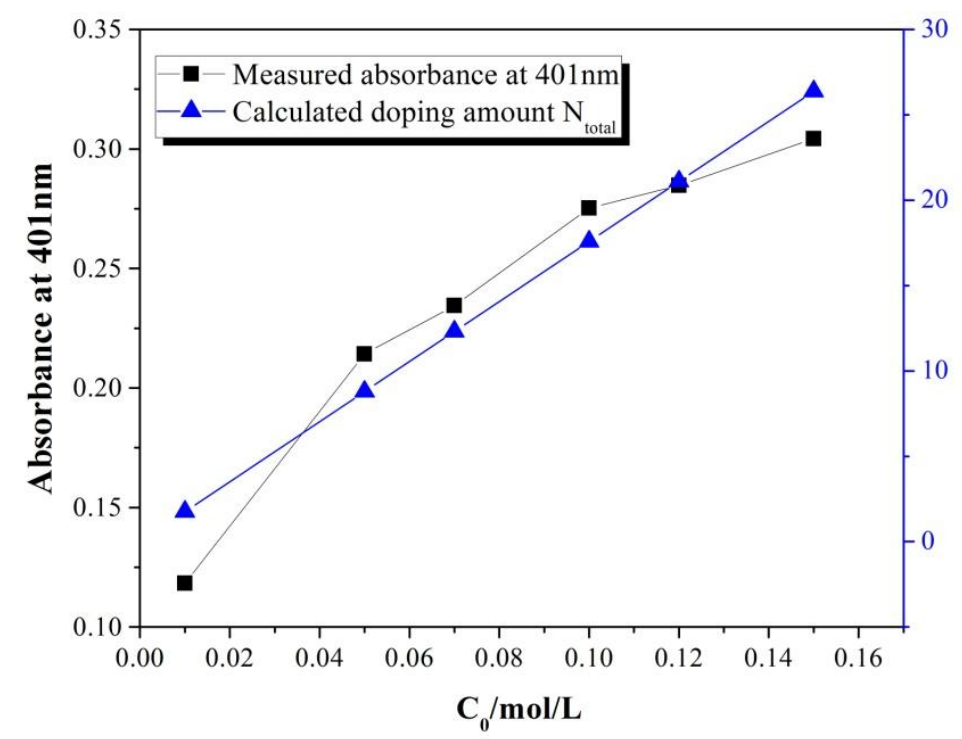

Fig.6 Measured absorbance of $401 \mathrm{~nm}$ and calculated doping amount vs. the concentration of $\mathrm{Sm}^{3+}$ solution

\section{Conclusions}

Theoretical analysis shows that the total doping amount of RE ions in high silica glass is the sum of diffusion fluxes and adsorption quantity of ion-exchange. According to Fick's law of diffusion, equation of mass conservation and mechanisms 
of ion-exchange, the theoretical model of RE ions in high silica glass was established. Combine pore structure parameters of porous glass samples, the concentrations of RE ions solution and adsorption times, the total doping amount of $\mathrm{Ce}^{3+}$ was calculated. The results show that the adsorption quantity of ion-exchange is only about one-tenth of diffusion fluxes. For increasing the doping amount of RE ions in high silica glass, adding the doping solution concentration is the easiest way and adding the specific surface area of porous glass is not an efficient method.

Besides, glass samples with different content of $\mathrm{Ce}^{3+}$ and $\mathrm{Sm}^{3+}$ were prepared by immersing the same porous glasses into different concentrations of $\mathrm{Ce}^{3+}$ solution and $\mathrm{Sm}^{3+}$ solution. The results indicate that the absorbance of different samples grow in line with doping amount growth, which verifies the correctness of adsorption model, qualitatively.

\section{Acknowledgements}

This work is supported by National Science Foundation of China (No. 61007030), National Science Foundation of Chongqing City (No.cstc2013jcyjA40043) and Fundamental Research Funds for the Central Universities of China (No.106112015CDJXY120005 and No. CDJZ11120002)

\section{References}

[1]L. Nagli, D. Bunimovich, A. Katzir et al., Journal of Non-Crystalline Solids 217 (1997) 208-214.

[2]L. Y. Yang, M. Yamashita, and T. Akai, Optics Express 17 (2009) 6688-6695.

[3]Q. Zhang, G. R. Chen, G. P. Dong et al., Chemical Physics Letters 482 (2009) 228-233.

[4]Q. Zhang, Y. B. Qiao, B. Qian et al., Journal of Luminescence 129 (2009) 1393-1397.

[5]W. Liu, D. Chen, H. Miyoshi et al., J. Non-Cryst. Solids. 352 (2006) 2969-2976.

[6]L. Jin, X.-h. Lei, L.-j. Ren et al., Spectroscopy and Spectral Analysis 34 (2014) 34-38.

[7]D. Chen, H. Miyoshi, T. Akai et al., Appl. Phys. Lett. 86 (2005) 2319081-2319083.

[8]Q. Zhang, Y. Qiao, B. Qian et al., J. Lumin. 129 (2009) 1393-1397.

[9]X. Q. Zeng, F. Y. Lin, F. X. Gan et al., Chin. Phys. Lett. 19 (2002) 1672-1674.

[10]Z. Liu, N. Dai, H. Luan et al., Optics Express 18 (2010) 21138-21146. 
[11]D. Chen, L. Yang, M. Peng et al., Journal of Rare Earths 24 (2006) 191-195.

[12]P. A. Monson, Microporous and Mesoporous Materials 160 (2012) 47-66.

[13]Z. G. Zhao, Adsorption principle of application (2005) 75-115.

[14]E. S. Kikkinides, M. E. Kainourgiakis, and A. K. Stubos, Langmuir 19 (2003) 3338-3344.

[15]B. Coasne and R. J. Pellenq, J Chem Phys 121 (2004) 3767-3774.

[16]L. D. Gelb and R. Salazar, Journal of the International Adsorption Society 11 (2005) 283-288.

[17]J. W. Jiang and S. I. Sandler, Langmuir 22 (2006) 5702-5707.

[18]F. Zhu, Y. Zhou, Q. Feng et al., Physics Letters A 377 (2013) 2324-2328.

[19]F. Zhu, Journal of Power Sources 243 (2013) 887-890.

[20]M. F. Hazenkamp and G. Blasse, Chem. Mater. 2 (1990) 105-110.

[21]N. Marmier, A. Delisee, and F. Fromage, Journal of colloid and interface science 212 (1999) 228-233.

[22]R. Garcia-Valls, A. Hrdlicka, J. Perutka et al., Analytica Chimica Acta 439 (2001) 247-253.

[23] Adachi G, Imanaka N. and Kang Z., Binary rare earth oxides (2004)129.

[24]E. R. Nightingale, Journal of Physical Chemistry 63 (1959) 1381-1387.

[25]R. D. Shannon, Acta Crystallographica Section A 32 (1976) 751-767.

[26]A. G. Volkov, S. Paula, and D. W. Deamer, Bioelectrochemistry and Bioenergetics 42 (1997) 153-160.

[27]B. Tansel, J. Sager, T. Rector et al., Separation and Purification Technology 51 (2006) 40-47.

[28]T. Wang, X. L. Pu and S. L. Zhu, Higher delivery process principle (2004).

[29]J. N. Chen, Principles of Transfer Course (2003).

[30]M. Takeuchi, G. Martra, S. Coluccia et al., Journal of Physical Chemistry B 109 (2005) 7387-7391.

[31]Kondou, S., T. Ishikawa, and I. Abe., Adsorption Science (2001) 26.

[32]S. Q. Bai, Chemical Analysis (2000)277-279.

[33]L. Ren, X. Lei, X. Du et al., Journal of Luminescence 142 (2013) 150-154.

[34]A. C. P. Rocha, L. H. C. Andrade, S. M. Lima et al., Optics Express 20 (2012) 1034-1041.

[35]Z. Zhu, Y. Zhang, Y. Qiao et al., Journal of Non-Crystalline Solids 358 (2012) 1550-1553.

[36]Z. Cui, R. Ye, D. Deng et al., Journal of Alloys and Compounds 509 (2011) 3553-3558. 